CAR-TR-797

Sept. 1995

CS-TR-3542

\title{
Windows of Opportunity in Electronic Classrooms
}

\author{
Ben Shneiderman*, Maryam Alavi§, Kent Norman † and Ellen Yu Borkowskif \\ Human-Computer Interaction Laboratory \\ Department of Computer Science*, Institute for Systems Research* \\ College of Business§, Department of Psychology $\dagger$ \\ Computer Science Center $f$ \\ University of Maryland, College Park, MD 20742-3255
}

\begin{abstract}
In our seven year effort to build electronic classrooms we tried to balance the pursuit of new technologies with the exploration of new teaching/learning styles while providing the necessary infrastructure for faculty training and support, and collecting ample evaluation data to guide our transformation. This experience has led to a growing community of faculty users, widespread student acceptance, and administration support for expansion.

After four years of usage by 44 faculty ( 20 tenured, 9 untenured, 15 other staff) from 16 departments offering 122 courses with over 4010 students we are ready to report on the lessons we have learned. Courses filled most slots from 8am to 10pm, and were as diverse as The Role of Media in the American Political Process, Chinese Poetry into English, Marketing Research Methods, Database Design, and Saving the Bay.
\end{abstract}

Communications of the ACM, Log on Education column, vol. 38, \# 11 (Nov. 1995) 19-24.

*Send Correspondence to Ben Shneiderman, ben@ cs.umd.edu 


\section{Introduction}

Paradigm-shifting landmark buildings are cherished by their occupants and remembered because they reshape our expectations of schools, homes, or offices. Classic examples include Thomas Jefferson's communal design of the "academical village" at University of Virginia where faculty and students lived close to classrooms, Frank Lloyd Wright's organic harmony with nature in Fallingwater (in western Pennsylvania) where the waterfall sounds and leafy surroundings offered a stress-reducing getaway for an urban executive, or Kevin Roche's open glass-walled Ford Foundation (in New York City) that promoted new team-oriented management strategies.

Current opportunities for architectural paradigm shifts are often tied to information and communications enhancements. At many universities there is a great rush to create electronic classrooms. Sometimes these combine computerbased multimedia lecture tools with audio-visual devices connected to a projector, such as Fred Hofstetter's PODIUM project at the University of Delaware. In other cases there are networked computers for each student as in Nunamaker's electronic meeting rooms at the University of Arizona or Trent Batson's ENFI Project at Gallaudet University. The potential for a paradigm shift in education evokes passion from devotees, but there is ample reason for skepticism and resistance.

In our seven year effort to build electronic classrooms we tried to balance the pursuit of new technologies with the exploration of new teaching/learning styles while providing the necessary infrastructure for faculty training and support, and collecting ample evaluation data to guide our transformation. This experience has led to a growing community of faculty users, widespread student acceptance, and administration support for expansion.

After four years of usage by 44 faculty (20 tenured, 9 untenured, 15 other staff) from 16 departments offering 122 courses with over 4010 students we are ready to report on the lessons we have learned. Courses filled most slots from $8 \mathrm{am}$ to 10pm, and were as diverse as The Role of Media in the American Political Process, Chinese Poetry into English, Marketing Research Methods, Database Design, and Saving the Bay.

There is no perfect floorplan that revolutionizes education, but faculty members who have used the electronic classrooms have explored novel teaching/learning styles that can create more engaging experiences for students. While traditional lectures with or without discussion will remain common, electronic classroom technologies can bring fresh paint to lectures, while opening transformational windows to active individual learning, small group collaborative learning, and entire class collaborative learning.

\section{Laying the Foundation}

During the 1980s, the University of Maryland joined many institutions in building workstation labs and classrooms with computers plus projectors for teaching software packages. By 1988 our Steering Committee believed that new teaching strategies for many disciplines could emerge in an advanced electronic classroom with well-integrated hardware, software, and networking. AT\&T generously supported our first electronic classroom, which was called the AT\&T Teaching Theater, reflecting our initial goal of supporting better lectures - we used the performance metaphor to elevate the role of the instructor. The construction of the second classroom was supported by IBM as part of their Total Quality Management (TQM) in Education Grant.

The first classroom was equipped with 22 AT\&T 386-based computers (recently upgraded to AT\&T Globalyst Pentium-based computers with $16 \mathrm{MB}$ of RAM and a $570 \mathrm{MB}$ hard disk). The second classroom was equipped with 22 IBM Ultimedia 486-based computers (with $16 \mathrm{MB}$ of RAM, 200MB hard disk). Both classrooms have 
high resolution monitors/projectors (768 x 1024 pixels), Microsoft Windows 3.1, and are networked together with the instructor's workstations plus two large ( 4 by 6 feet) displays (see photo). Fortunately, we insisted on a LINK video switcher so the instructor can view or take over any student's computer and show it on the large displays.

While circumstances may vary, we recommend four physical design decisions:

- two students per computer to encourage discussion (the AT\&T classroom had 4 tiered rows of 5 work areas and the IBM classroom had two concentric U-shaped rows of 6 and 14 work areas).

- monitors are partially recessed into the desks for better sightlines among students and instructors.

- computers are in an adjoining room to reduce bulk, heat, and noise, while improving security.

- connection to the campus net means that floppy disk access and printing are not needed.

Other features included lighting to minimize glare, sound absorbing walls and carpets, desks to permit wheelchair access, upholstered adjustable swivel chairs, and ample air conditioning. A video console with 3 cameras, ceiling microphones \& a wireless microphone allows faculty to record classes.

Familiar efficiency-related aspects of the electronic classrooms were electronic grade keeping, online class rosters with student photos, and some attempts at online tests. Online course outlines, bibliographies, assignments, datasets, etc. were commonly used. As with other networked environments, students could access these any time of day and were able to keep up if they missed a session or were sick at home. No more delayed homework because the student lost a handout.

\section{Emergent styles of teaching/learning}

As with any research project, excitement emerges as initial expectations give way to new realities. We originally called our electronic classrooms Teaching Theaters, but as faculty experimented with new teaching styles the Steering Committee shifted to the term Learning Theaters to convey an increased emphasis on student-centered learning styles. We kept the term Theaters to acknowledge the key role of faculty. They may have shifted from the "sage on the stage to the guide on the side" but they are still the directors of the process and the source of motivational goal setting. Most faculty acknowledge spending more preparation time to use the electronic classroom especially in their first semester, but one wrote, it is "well worthwhile in terms of greater learning efficiency in the Theater." The teaching/learning styles we identified included improved traditional lectures, but the paradigm shifting styles were active individual learning, small group collaborative learning, and entire class collaborative learning:

1) Traditional lectures with discussions do occur, but most faculty are eager to try something fresh in this elegant and novel environment. Simple and safe explorations include expanded use of videotapes, demonstrations of software, and use of the video visualizers to show images from books and newspapers. Some faculty hackers shifted from plastic slides to PowerPoint for presenting their lectures with the advantages that changes can be made even while class is in session and students can be given access to the slides on the network server for electronic notetaking and annotation.

2) More active individual learning experiences include using software during class time to write essays in English or poems in a foreign language, find antecedents of Impressionism in an art history library of 9000 images, run business simulations to increase product quality, perform psychological statistical analyses, do landscape design with computer assisted design and graphics packages, compose computer programs, and search the internet. A common strategy (e.g. Norman, K., Navigating the educational space with HyperCourseware, Hypermedia 6, 1, January 1994, 35-60) is to assign time limited tasks 


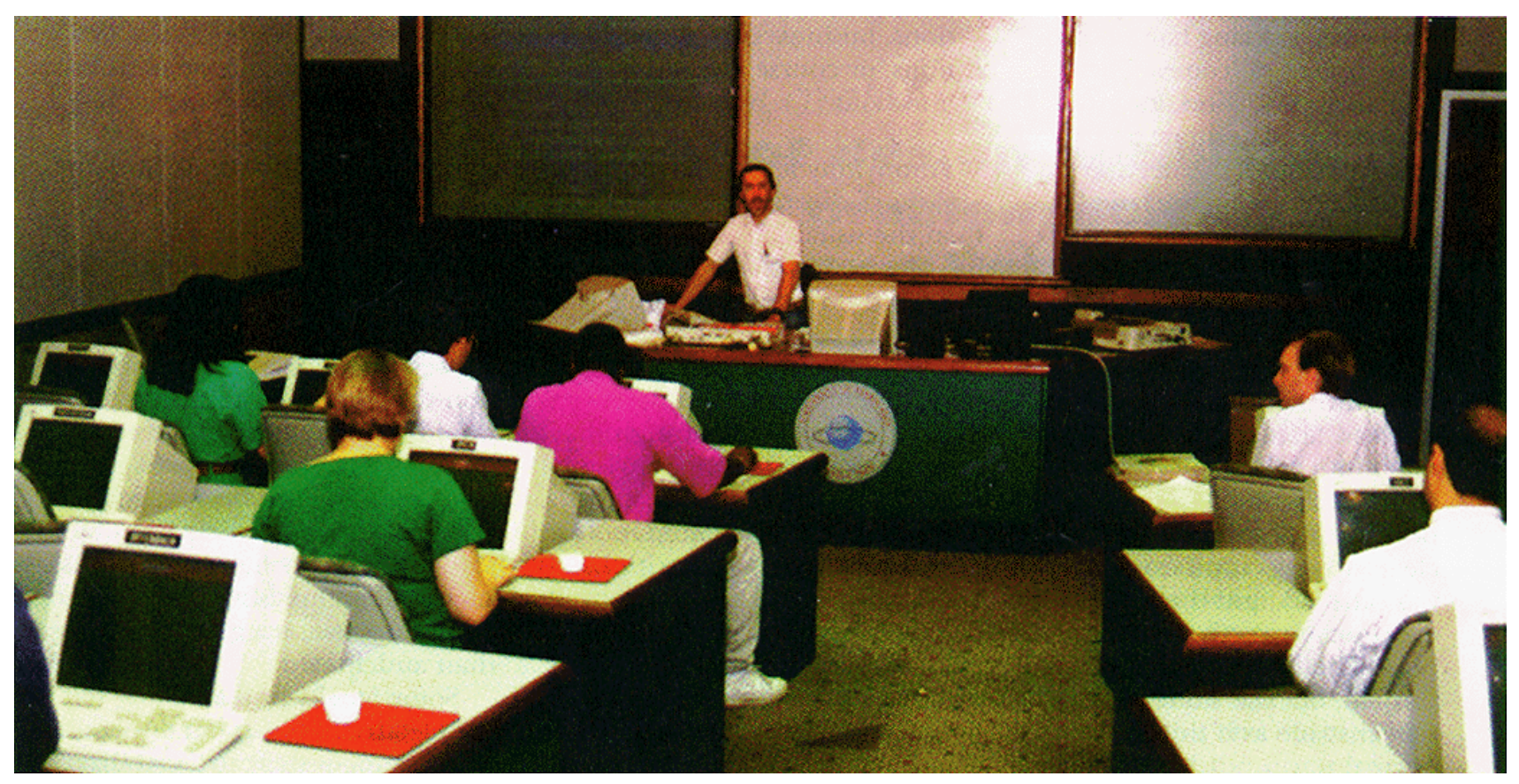

The AT\&T Learning/Teaching Theater at the University of Maryland, College Park.

(3-10 minutes), and then use the video switcher to review the students' work, give individual help when necessary, and show the students' work to the entire class. The transformational breakthrough is opening the learning process by rapidly showing many students's work to the entire class. This generates student and faculty anxiety the first time, but quickly becomes normal. Seeing and critiquing exemplary and ordinary work by fellow students provides feedback that inspires better work on subsequent tasks. It takes only one button press to bring up a workstation making it is quick and even cognitively less demanding that a mouse click.

3) Small group collaborative learning experiences include having pairs of students work together at a machine on a time limited task. Like other researchers we found that pairs learn better because they can discuss their problems, learn from each other, and split their roles into problem solvers and computer operators. With paired teams the variance of completion time for tasks is reduced compared to individual use and fewer students get stuck in completing a task. Verbalization of problems has often been demonstrated to be advantageous during learning and is an important job skill to acquire for modern team-oriented organizations.
Innovative approaches with larger teams include simulated hostage negotiations with terrorist airplane hijackers in a course on conflict resolution, and business trade negotiations in a United Nations format for a course on commercial Spanish. Teams work to analyze situations, develop position statements online, and communicate their positions to their adversaries by the network. Students become invested in their positions while working hard to produce desired outcomes. They gain an appreciation of the importance of accurate and timely data, plus the need to understand their adversaries's positions.

A memorable moment occurred in the first programming course in which 10 teams wrote components and sent them through the network to the lead team who combined them into a 173line Pascal program all in 25 minutes. The class performed a walkthrough to clean up bugs till everyone was satisfied, and the program executed correctly the first time. The instructor was thrilled, but the students took this in stride as if this was the normal way to work (Shneiderman, B., Education by Engagement and Construction: Experiences in the AT\&T Teaching Theater, In Maurer, H. , Editor, Educational Multimedia and Hypermedia Annual 1993, 
Association for the Advancement of Computing in Education, Charlottesville, VA, 471-479, see http://www.cs.umd.edu/projects/hcil). Typical final student projects in this course were four times as long as in traditional classes. Student comments about the electronic classroom included: "This is a great room...I brag to my friends about it...I feel sorry for all those other students that do not have access to this facility TOO BAD."

4) Entire class collaborative learning experiences focus on the use of groupware products (VisionQuest from Intellect Corp. and GroupSystems from Ventana Corp.) to support brainstorming in which every student's anonymous response to a question is shown on the large display. In minutes, dozens of diverse 1-2 line suggestions are brought forward for further discussion, refinement, or voting. Some faculty (e.g. Alavi) use this approach to start their classes by asking which issues in the previous class or homework require further discussion. Within minutes many issues are raised, students can gauge their understanding compared to others, and the sense of engagement in shaping the course is dramatically heightened. Other faculty deal with content questions, business case study solutions, or course evaluation questions.

Anonymity leads to a livelier and more diverse set of responses than the usual hand raising, and if a reasonable question is asked the rapid flood of comments is almost always stimulating. Good questions should be clear enough that students know what is expected, and open enough that there are several answers. Wisecracking students can be sharp and funny, but other students are often quick to respond with balancing comments.

Other collaborative learning experiences depend on software developed by support staff (led by Borkowski). In the One Minute Paper each student writes a paragraph in response to a question and can submit it signed or anonymously. Instructors review the submissions on their workstation and select responses to show everyone. The Multiperson Chat program allows the entire class or subgroups to utilize electronic discussion rooms in separate windows . Comments may be signed or anonymous, and the groups can last a few minutes or the whole semester while generating a log of the discussion for later review. These styles overcome the dual problems of traditional discussions: a small number of students frequently respond and a large fraction of the class never participates. Electronic brainstorming and chat groups consistently produce higher participation and motivation. Faculty have to readjust their expectation of how much time to allocate to these activities because of the vigorous discussions that they generate.

\section{Community building and infrastructure support}

Our naive assumption that improved lectures was the main goal changed as faculty tried collaborative teaching methods and talked about them to each other. Faculty who had used paperbased collaborations appreciated the smoothness of showing typed student submissions to the whole class. Faculty who had not used collaborative methods were lured in by the ease and liveliness of an anonymous electronic brainstorming session. Our initial assumption that students and faculty would value feedback buttons and meters to indicate comprehension levels has not been validated. But more active participation by students using the collaborative tools like the One Minute Paper and Multichat is a greater success than anticipated.

Some faculty find that adapting to the electronic classroom environment changes their styles so that they teach differently even in traditional classrooms. Other faculty vow that they will never teach in a traditional classroom. We and most of our colleagues want to continue teaching in these electronic classrooms. We have discovered that more than our teaching styles have changed - we've often changed our attitudes about what teaching is and revised the content of 
the courses we teach. Many faculty have higher expectations for student projects. Some have become evangelists within their disciplines about teamwork plus the accompanying communications skills.

On the negative side, a math professor who used the computers only to do occasional demonstrations returned to teaching in a traditional classroom where he had much more blackboard space. Some reluctant colleagues express resistance to change their teaching styles and anticipate a large effort to use the electronic classrooms.

To help ensure success of new faculty users, we budget for a high level of support staff, faculty training, and software acquisition. Equipment maintenance and some software development complete the infrastructure needs. The campuswide Computer Science Center staff manages the process. Students are hired and trained to provide daily support for courses, avoiding the need for faculty to deal with failing machines or network glitches.

The Steering Committee reviews proposals for using the Learning Theaters and resolves schedule conflicts by time shifts to accommodate as many courses as possible. We preserve approximately $10 \%$ of the time for instructor preparation and another $10 \%$ for demonstrations to visitors or use by outside groups.

We prepare brochures, send email announcements, build websites (http:// www.umcp.umd.edu/TeachTech/Welcome.html), offer seminars, and organize annual Technology in Teaching conferences to promote the electronic classrooms and other initiatives. Faculty in varied disciplines describe their teaching styles and experiences. Having dedicated staff and student aides facilitates all these activities.

\section{Evaluations and improvements}

Evaluations were always part of our plan, from standard course evaluations, to use of
VisionQuest, and specially prepared questionnaires. One faculty member conducted a controlled study with 127 students (Alavi, M., Computer mediated collaborative learning: An empirical evaluation, MIS Quarterly 18, 2, June 1994, 159-173) indicating that electronic classroom students had higher perceived skill development, self-reported learning, and evaluation of classroom experience than students in a collaborative learning traditional classroom. Electronic classroom students also had a statistically significantly higher final exam grade. Popular features were the electronic note-taking, ability for interactivity, idea sharing, and brainstorming. Other studies led to at least ten published reports by individual faculty.

Faculty evaluations and experiences revealed problems. Network access from outside the classrooms and file sharing methods within the classroom had to be simplified. Many students wanted more deskspace while many faculty found the imposing instructor workspace to be too large. We may have been victims of our theater metaphor, but this problem was remedied in our second electronic classroom. Room lighting controls were simplified, but we still have difficulty making the white board readable while using the large displays or viewing videos. Students generally were positive and often enthusiastic: "Everyone should have a chance to be in here at least once...Great tech. Great education technique...Easy to use, but tends to crash and die at times... The theater is really the best thing that I could think of to improve the ability to teach interactively. Even though there were a few humps to get over at the beginning - it was well worth the effort (and money)."

\section{Conclusions}

We and others were the architects and the clients for these electronic classrooms. Living in the environment we created forces us and other faculty to see the impact of design decisions, encourages creative problem solving, and clarifies our vision of electronic classroom design for future construction. Our third and fourth elec- 
tronic classrooms will soon be functioning and two more are under construction. It might be a good idea for other architects to live in buildings they designed.

Current architectural challenges are to deal with larger classrooms, allow students to plug in their laptops, and enable movement of workstations to form physical clusters. Faculty want richer software tools, easier methods of collaboration, larger image databases, and faster network access. Cost is a concern, but we see prices dropping and payoffs increasing. We anticipate that students and faculty will be attracted to institutions with such facilities.

The largest paradigm shift is not in reshaping physical buildings or the hardware/software, but in ourselves. The faculty users feel that there is no turning back. They continue to find novel corridors towards more active individual and small group learning experiences, plus entire class collaborative learning that provide high levels of engagement. Several have applied these concepts for distance learning situations using video conferencing (e.g. Alavi and Norman), email, and the World Wide Web (e.g. see http://www.cs.umd.edu/projects/eve/ vrtp.html), while others have explored serviceoriented authentic projects in the university community and beyond (e.g. Shneiderman).

We were taught that form should follow function, but we're learning a transformatinal principle: new forms can inspire new functions.

Acknowledgements: We are especially grateful for the early influence of Glenn Ricart and Ron Weissman who were key figures in the original proposal to AT\&T. The excellence of these electronic classrooms is due to the devoted and continuing efforts of many people, especially Walt Gilbert of the Computer Science Center and Jim Greenberg of the Center for Teaching Excellence. Other contributors were Theo Stone and Jennifer Fajman. We appreciate the vigorous guidance of Elliot Soloway in reshaping the presentation

\section{References}

1. Alavi, M. Computer mediated collaborative learning: An empirical evaluation. MIS Quart. 18, 2 (Jun. 1994), 159-173.

2. Norman, K. Navigating the educational space with HyperCourseware. Hypermedia 6 (Jan. 1994), 35-60.

3. Shneiderman, B. Education by engagement and construction: Experiences in the AT\&T teaching theater. In H. Maurer, ed., Educational Multimedia and Hypermedia Annual. Association for the Advancement of Computing in Education, Charlottesville, Virg., 1993, 471-479; see http://www.cs.umd.edu/projects/hcil 